\title{
EXPORT AND HEDGING DECISIONS UNDER CORRELATED REVENUE AND EXCHANGE RATE RISK
}

\author{
Kit Pong Wong* \\ School of Economics and Finance, University of Hong Kong, Hong Kong
}

\begin{abstract}
This paper examines the behavior of a competitive exporting firm under joint revenue and exchange rate risk. The firm can trade unbiased currency futures contracts for hedging purposes. We show that neither the separation theorem nor the full-hedging theorem holds when the revenue shock prevails. If the correlation between the revenue shock and the random spot exchange rate is non-positive, the firm optimally produces less than the benchmark level when the revenue shock is absent. If, in addition, the firm is prudent, the optimal futures position is an under-hedge. Finally, we derive sufficient conditions under which the firm's optimal output level is higher in the presence than in the absence of the revenue shock. Operational hedging and financial hedging as such interact in a complicated way to better cope with the multiple sources of uncertainty faced by the firm.
\end{abstract}

Keywords: exports; futures hedging; multiple sources of uncertainty; prudence

JEL classification numbers: D21, D24, D81, F31

\section{INTRODUCTION}

Since the seminal work of Holthausen (1979), there has been a large body of research on the hedging behavior of the competitive firm under price uncertainty $\grave{a}$ la Sandmo (1971). One important strand of this literature extends the analysis to study the export and hedging decisions of a competitive exporting firm under exchange rate uncertainty (see, e.g., Benninga et al., 1985; Broll, 1992; Broll and Zilcha, 1992; Katz and Paroush,

\footnotetext{
${ }^{*}$ Correspondence: Kit Pong Wong, School of Economics and Finance, University of Hong Kong, Pokfulam Road, Hong Kong. Tel.: +852 2859 1044; Fax: +852 2548 1152; Email: kpwong@econ.hku.hk. The author would like to thank Axel Adam-Müller, Udo Broll, Gabriel Talmain (Editor-in-Charge), three anonymous referees, and seminar participants at the Shanghai University of Finance and Economics for their helpful comments and suggestions. The usual disclaimer applies.
} 
1979; Kawai and Zilcha, 1986; Viaene and Zilcha, 1998; Wong, 2007). Two notable results emanate. First, the separation theorem states that the firm's optimal production decision depends neither on the risk attitude of the firm, nor on the incidence of the underlying exchange rate uncertainty. Second, the full-hedging theorem asserts that the firm should fully hedge against its exposure to the exchange rate risk if the currency forward/futures market is unbiased. ${ }^{1}$

The purpose of this paper is to examine the robustness of the separation and fullhedging theorems when the competitive exporting firm is confronted with not only the exchange rate uncertainty but also a multiplicative shock to its foreign currency revenue as in Adam-Müller (1997). Such a revenue shock may come from various sources: uncertain output prices, political uncertainty in the foreign country, credit risk of the importing firm, and many others. Unlike Adam-Müller (1997), we allow this shock to be correlated with the exchange rate uncertainty. For example, the prevalence of incomplete exchange rate pass-through gives rise to a negative correlation between the random spot exchange rate and the prevailing output price (Wong, 2003). As documented by Goldberg and Knetter (1997), a 10-percent depreciation of the US dollar would be associated with an increase in US import prices of approximately 5 percent at the aggregate level. ${ }^{2}$ Using annual political and exchange rate risk ratings from the International Country Risk Guide of the Political Risk Services, Kim and Song (2010) document a positive correlation between these two measures. While the exchange rate risk is hedgeable by trading currency futures contracts, the revenue shock is neither hedgeable nor insurable.

When the revenue shock prevails, both the separation and full-hedging theorems fail to hold. We show that the correlation between the revenue shock and the random spot exchange rate plays a pivotal role in determining the firm's optimal export and hedging decisions. Specifically, if this correlation is non-positive, the firm optimally produces less as compared to the benchmark output level when the revenue shock is absent. Doing so allows the firm to limit its risk exposure to the unhedgeable revenue shock. When the

\footnotetext{
${ }^{1}$ In a single-period context, currency forward contracts are identical to currency futures contracts.

${ }^{2}$ Gust et al. (2010) and Marazzi and Sheets (2007) find that the sensitivity of US import prices to the exchange rate has gradually declined from 0.5 in the 1980 s to 0.2 in the past decade.
} 
correlation between the revenue shock and the random spot exchange rate is positive, we derive sufficient conditions under which the firm optimally produces more, not less, than the benchmark level. The firm as such uses operational hedging to complement financial hedging so as to effectively manage the multiple sources of uncertainty. ${ }^{3}$

We show that there is a correlation motive that induces the firm to sell more or less the currency futures contracts, depending on whether the correlation between the revenue shock and the random spot exchange rate is positive or negative, respectively. If the firm's preferences satisfy the reasonable property of prudence (Kimball, 1990, 1993), the prudent firm has a precautionary motive that calls for a long futures position. The correlation motive reinforces the precautionary motive should the correlation between the revenue shock and the random spot exchange rate be non-positive, thereby rendering the optimality of an under-hedge for the prudent firm. However, if the correlation is positive, the correlation motive counteracts the precautionary motive, thereby making the prudent firm's optimal futures position indeterminate.

This paper is closely related to the literature on cross-hedging wherein firms use forward/futures contracts on related currencies to cross-hedge their exchange rate risk exposure (see, e.g., Anderson and Danthine, 1981; Broll, 1997; Broll and Wong, 1999; Broll et al., 1999; Chang and Wong, 2003). Adam-Müller and Nolte (2011) examine cross-hedging under multiplicative basis risk. One of their specifications of multiplicative basis risk is a special case of ours in which the revenue shock and the random spot exchange rate are independent. ${ }^{4}$ In this case, Adam-Müller and Nolte (2011) show that the prudent firm optimally opts for an under-hedge, which is consistent with our findings. Wong (2013) examines cross-hedging when there are home, foreign, and third currencies. In the case of imperfect cross-hedging when futures contracts between the foreign and third currencies are missing, Wong (2013) shows that a full-hedge is suboptimal even when the random spot exchange

\footnotetext{
${ }^{3}$ Operational hedging is typically formulated in a multi-period context that allows for real options and/or a time structure of uncertainty resolution. Since our model is a single-period one, some caveats are called for when the firm's output decision is interpreted as an operational measure of risk management.

${ }^{4}$ Specification (M.1) in Adam-Müller and Nolte (2011) is given by $\tilde{P}=\beta \tilde{F} \tilde{\theta}$, where $\tilde{\theta}$ and $\tilde{F}$ are independent. By setting $\beta=1$ and $\tilde{F}=\tilde{S}$, specification (M.1) is simply a special case of ours wherein $\tilde{\theta}$ and $\tilde{S}$ are independent. Adam-Müller and Nolte (2011), however, do not consider the firm's production decision.
} 
rates are independent. This case in Wong (2013) is identical to our setting. We extend the characterization of the firm's optimal futures position to the general case wherein the random spot exchange rates are allowed to be correlated.

The rest of this paper is organized as follows. The next section delineates the model of a competitive exporting firm under joint revenue and exchange rate risk. The firm can trade unbiased currency futures contracts for hedging purposes. Section III derives the firm's optimal export decision. Section IV characterizes the firm's optimal futures position. Section V constructs two reasonable examples that have closed-form solutions. The final section concludes.

\section{THE MODEL}

Consider a competitive exporting firm that operates for one period with two dates, 0 and 1. The firm possesses a von Neumann-Morgenstern utility function, $U(\Pi)$, defined over its home currency profit at date $1, \Pi$. The firm is risk averse so that $U^{\prime}(\Pi)>0$ and $U^{\prime \prime}(\Pi)<0$ for all $\Pi>0 .^{5}$

To begin, the firm produces a single commodity according to a deterministic cost function, $C(Q)$, in the home country, where $Q \geq 0$ is the output level and $C(Q)$ is compounded to date 1 . The firm's production technology exhibits decreasing returns to scale so that $C(Q)$ satisfies that $C(0)=C^{\prime}(0)=0$, and that $C^{\prime}(Q)>0$ and $C^{\prime \prime}(Q)>0$ for all $Q>0$. The firm sells its entire output in a foreign country at a per-unit price, $P$, at date 1 , where $P>0$ is exogenously fixed and denominated in the foreign currency. As in Adam-Müller (1997), the firm's foreign currency revenue, $\tilde{\theta} P Q$, is subject to a multiplicative shock, $\tilde{\theta}$, which is a positive random variable with unit mean. ${ }^{6}$ The spot exchange rate, $\tilde{S}$, expressed in units of the home currency per unit of the foreign currency at date 1, is also a positive

\footnotetext{
${ }^{5}$ The risk-averse behavior of the firm can be motivated by managerial risk aversion (Stulz, 1984), corporate taxes (Smith and Stulz, 1985), costs of financial distress (Smith and Stulz, 1985), and/or capital market imperfections (Froot et al., 1993; Stulz, 1990). See Tufano (1996) for evidence that managerial risk aversion is a rationale for corporate risk management in the gold mining industry.

${ }^{6}$ Throughout the paper, random variables have a tilde $\left({ }^{\sim}\right)$ while their realizations do not.
} 
random variable. The firm as such is confronted with these two sources of uncertainty that are possibly correlated. Let $\mathrm{E}(\cdot), \operatorname{Var}(\cdot)$, and $\operatorname{Cov}(\cdot, \cdot)$ be the expectation, variance, and covariance operators with respect to the joint cumulative distribution function of $\tilde{\theta}$ and $\tilde{S}$, respectively.

While the revenue shock, $\tilde{\theta}$, is neither hedgeable nor insurable, the firm can hedge against its risk exposure to the random spot exchange rate, $\tilde{S}$, by trading unbiased currency futures contracts at date 0 . Specifically, each currency futures contract calls for delivery of $\mathrm{E}(\tilde{S})$ units of the home currency per unit of the foreign currency at date 1. The firm's random profit at date 1 , denominated in the home currency, is given by

$$
\tilde{\Pi}=\tilde{\theta} \tilde{S} P Q+[\mathrm{E}(\tilde{S})-\tilde{S}] H-C(Q)
$$

where $H$ is the number of the currency futures contracts sold (purchased if negative) by the firm at date 0 . We refer to the futures position, $H$, as an under-hedge, a full-hedge, or an over-hedge, depending on whether $H$ is smaller than, equal to, or greater than the expected foreign currency revenue, $P Q$, respectively.

The firm's ex-ante decision problem is to choose an output level, $Q \geq 0$, and a futures position, $H$, at date 0 so as to maximize the expected utility of its home currency profit at date 1:

$$
\max _{Q \geq 0, H} \mathrm{E}[U(\tilde{\Pi})]
$$

where $\tilde{\Pi}$ is given by Eq. (1). The first-order conditions for program (2) are given by

$$
\mathrm{E}\left\{U^{\prime}\left(\tilde{\Pi}^{*}\right)\left[\tilde{\theta} \tilde{S} P-C^{\prime}\left(Q^{*}\right)\right]\right\}=0
$$

and

$$
\mathrm{E}\left\{U^{\prime}\left(\tilde{\Pi}^{*}\right)[\mathrm{E}(\tilde{S})-\tilde{S}]\right\}=0
$$

where an asterisk $\left(^{*}\right)$ signifies an optimal level. The second-order conditions for program (2) are satisfied given risk aversion and the strict convexity of the cost function. 


\section{OPTIMAL EXPORT DECISION}

As a benchmark, we consider first the case that the revenue shock is absent, i.e., $\tilde{\theta} \equiv 1$. In this case, we substitute Eq. (6) into Eq. (5) to obtain the optimal output level, $Q^{\circ}$, that solves $C^{\prime}\left(Q^{\circ}\right)=\mathrm{E}(\tilde{S}) P$. This is simply the separation theorem in that $Q^{\circ}$ depends neither on the firm's risk attitude nor on the underlying exchange rate uncertainty.

We write Eqs. (3) and (4) as ${ }^{7}$

$$
\mathrm{E}(\tilde{S}) P+\operatorname{Cov}(\tilde{\theta}, \tilde{S}) P-C^{\prime}\left(Q^{*}\right)=-\frac{\operatorname{Cov}\left[U^{\prime}\left(\tilde{\Pi}^{*}\right), \tilde{\theta} \tilde{S}\right] P}{\mathrm{E}\left[U^{\prime}\left(\tilde{\Pi}^{*}\right)\right]}
$$

and

$$
\operatorname{Cov}\left[U^{\prime}\left(\tilde{\Pi}^{*}\right), \tilde{S}\right]=0
$$

respectively, where Eq. (5) follows from the fact that $\mathrm{E}(\tilde{\theta})=1$. Since the revenue shock is neither hedgeable nor insurable, the firm's home currency profit at date 1 must be stochastic. Eq. (1) implies that

$$
\begin{aligned}
\operatorname{Cov}\left[U^{\prime}\left(\tilde{\Pi}^{*}\right), \tilde{\Pi}^{*}\right] & =\operatorname{Cov}\left[U^{\prime}\left(\tilde{\Pi}^{*}\right), \tilde{\theta} \tilde{S}\right] P Q^{*}-\operatorname{Cov}\left[U^{\prime}\left(\tilde{\Pi}^{*}\right), \tilde{S}\right] H^{*} \\
& =\operatorname{Cov}\left[U^{\prime}\left(\tilde{\Pi}^{*}\right), \tilde{\theta} \tilde{S}\right] P Q^{*}<0,
\end{aligned}
$$

where the second equality follows from Eq. (6), and the inequality follows from $U^{\prime \prime}(\Pi)<0$. If $\operatorname{Cov}(\tilde{\theta}, \tilde{S}) \leq 0$, Eqs. (5) and (7) imply that $C^{\prime}\left(Q^{*}\right)<\mathrm{E}(\tilde{S}) P$. It then follows from the strict convexity of $C(Q)$ that $Q^{*}<Q^{\circ}$, thereby invoking our first proposition.

Proposition 1. The competitive exporting firm that can trade the unbiased currency futures contracts optimally produces less as compared to the benchmark case of no revenue shocks, i.e., $Q^{*}<Q^{\circ}$, if the revenue shock, $\tilde{\theta}$, and the random spot exchange rate, $\tilde{S}$, are either uncorrelated or negatively correlated.

\footnotetext{
${ }^{7}$ For any two random variables, $\tilde{X}$ and $\tilde{Y}$, we have $\operatorname{Cov}(\tilde{X}, \tilde{Y})=\mathrm{E}(\tilde{X} \tilde{Y})-\mathrm{E}(\tilde{X}) \mathrm{E}(\tilde{Y})$.
} 
To see the intuition for Proposition 1, we recast Eq. (1) as

$$
\tilde{\Pi}^{*}=\mathrm{E}(\tilde{S}) P Q^{*}-C\left(Q^{*}\right)+[\tilde{S}-\mathrm{E}(\tilde{S})]\left(P Q^{*}-H^{*}\right)+(\tilde{\theta}-1) \tilde{S} P Q^{*}
$$

The prevalence of the revenue shock induces the firm to cut down its output so as to limit the risk exposure that comes from the last term on the right-hand side of Eq. (8). Taking expectations on both sides of Eq. (8) yields

$$
\mathrm{E}\left(\tilde{\Pi}^{*}\right)=\mathrm{E}(\tilde{S}) P Q^{*}-C\left(Q^{*}\right)+\operatorname{Cov}(\tilde{\theta}, \tilde{S}) P Q^{*}
$$

since $\mathrm{E}(\tilde{\theta})=1$. If $\tilde{\theta}$ and $\tilde{P}$ are negatively correlated (uncorrelated), the last term on the right-hand side of Eq. (9) is decreasing in (invariant to) output, which reinforces (has no effect on) the firm's risk reduction incentive, thereby rendering $Q^{*}<Q^{\circ}$.

Given that the joint cumulative distribution function of $\tilde{\theta}$ and $\tilde{S}$ is completely general, we need to impose unduly strong restrictions on the firm's utility function in order to derive clear-cut results, particularly when $\tilde{\theta}$ and $\tilde{S}$ are positively correlated. To this end, we examine the tractable case that the firm possesses a quadratic utility function that takes on the generic form: $U(\Pi)=a \Pi-b \Pi^{2} / 2$, where $a$ and $b$ are positive constants such that $a-b \Pi>0$ for the relevant range of $\Pi>0$. We state and prove the following proposition.

Proposition 2. Given that the competitive exporting firm possesses the quadratic utility function, $U(\Pi)=a \Pi-b \Pi^{2} / 2$, and can trade the unbiased currency futures contracts, the firm optimally produces more (less) as compared to the benchmark case of no revenue shocks, i.e., $Q^{*}>(<) Q^{\circ}$, if the revenue shock, $\tilde{\theta}$, and the random spot exchange rate, $\tilde{S}$, satisfy that

$$
\begin{aligned}
\operatorname{Cov}(\tilde{\theta}, \tilde{S})>(<) & \left\{\frac{b Q^{\circ}}{a-b\left[\mathrm{E}(\tilde{S}) P Q^{\circ}-C\left(Q^{\circ}\right)\right]}\right\} \\
& \times\left\{\mathrm{E}\left[(\tilde{\theta}-1)^{2} \tilde{S}^{2}\right]-\frac{\operatorname{Cov}[(\tilde{\theta}-1) \tilde{S}, \tilde{S}]^{2}}{\operatorname{Var}(\tilde{S})}\right\}
\end{aligned}
$$

Proof. See Appendix A. 
Since the correlation coefficient between $(\tilde{\theta}-1) \tilde{S}$ and $\tilde{S}$ must be in $[-1,1]$, we have

$$
\operatorname{Corr}[(\tilde{\theta}-1) \tilde{S}, \tilde{S}]=\frac{\operatorname{Cov}[(\tilde{\theta}-1) \tilde{S}, \tilde{S}]}{\sqrt{\operatorname{Var}[(\tilde{\theta}-1) \tilde{S}] \operatorname{Var}(\tilde{S})}} \in[-1,1]
$$

Raising both sides of Eq. (11) to the power of 2 yields

$$
\operatorname{Corr}[(\tilde{\theta}-1) \tilde{S}, \tilde{S}]^{2}=\frac{\operatorname{Cov}[(\tilde{\theta}-1) \tilde{S}, \tilde{S}]^{2}}{\operatorname{Var}[(\tilde{\theta}-1) \tilde{S}] \operatorname{Var}(\tilde{S})} \leq 1
$$

Eq. (12) implies that

$$
\frac{\operatorname{Cov}[(\tilde{\theta}-1) \tilde{S}, \tilde{S}]^{2}}{\operatorname{Var}(\tilde{S})} \leq \operatorname{Var}[(\tilde{\theta}-1) \tilde{S}]<\mathrm{E}\left[(\tilde{\theta}-1)^{2} \tilde{S}^{2}\right]
$$

where the second inequality follows from $\operatorname{Var}[(\tilde{\theta}-1) \tilde{S}]=\mathrm{E}\left[(\tilde{\theta}-1)^{2} \tilde{S}^{2}\right]-\mathrm{E}[(\tilde{\theta}-1) \tilde{S}]^{2}$. Since $\mathrm{E}(\tilde{S}) P Q^{\circ}-C\left(Q^{\circ}\right)$ is the firm's expected home currency profit at date 1 , we have $a-b\left[\mathrm{E}(\tilde{S}) P Q^{\circ}-C\left(Q^{\circ}\right)\right]>0$. It then follows from Eq. (13) that the right-hand side of condition (10) is strictly positive. In words, condition (10) states that the firm optimally produces more (less) when the revenue shock is present than when it is absent should the correlation between the revenue shock, $\tilde{\theta}$, and the random spot exchange rate, $\tilde{S}$, be sufficiently (not too) large.

To see the intuition for Proposition 2, we write condition (10) as

$$
\frac{b}{a}<(>) \frac{\operatorname{Cov}(\tilde{\theta}, \tilde{S})}{\left[\mathrm{E}(\tilde{S}) P Q^{\circ}-C\left(Q^{\circ}\right)\right] \operatorname{Cov}(\tilde{\theta}, \tilde{S})+Q^{\circ}\left\{\mathrm{E}\left[(\tilde{\theta}-1)^{2} \tilde{S}^{2}\right]-\frac{\operatorname{Cov}[(\tilde{\theta}-1) \tilde{S}, \tilde{S}]^{2}}{\operatorname{Var}(\tilde{S})}\right\}}
$$

Since $Q^{\circ}$ solves $C^{\prime}\left(Q^{\circ}\right)=\mathrm{E}(\tilde{S})$, the right-hand side of condition (14) depends only on the joint cumulative distribution function of $\tilde{\theta}$ and $\tilde{S}$, and is independent of the firm's preferences. This term is non-positive if $\operatorname{Cov}(\tilde{\theta}, \tilde{S}) \leq 0$. In this case, condition (14) implies that $Q^{*}<Q^{\circ}$, which is consistent with the results of Proposition 1. If $\operatorname{Cov}(\tilde{\theta}, \tilde{S})>0$, condition (14) says that $Q^{*}$ is larger or smaller than $Q^{\circ}$ depending on whether $b / a$ is smaller or larger than a positive threshold, respectively. When $\operatorname{Cov}(\tilde{\theta}, \tilde{S})>0$, the last term on the right-hand side of Eq. (9) is increasing in the firm's output level. This counteracts and dominates (but does not dominate) the firm's risk reduction incentive if the firm is not 
too (sufficiently) risk averse, thereby implying that $Q^{*}>(<) Q^{\circ} .{ }^{8}$ Indeed, if the firm is risk neutral so that $a=1$ and $b=0$, condition $(10)$ reduces to $Q^{*}>(<) Q^{\circ}$ if $\operatorname{Cov}(\tilde{\theta}, \tilde{S})>(<) 0$.

\section{OPTIMAL HEDGING DECISION}

For tractability, we follow Chang and Wong (2003) and Wong (2003) to assume that the

revenue shock, $\tilde{\theta}$, and the random spot exchange rate, $\tilde{S}$, are related in the following manner:

$$
\tilde{\theta}=1+\beta[\tilde{S}-\mathrm{E}(\tilde{S})]+\tilde{\varepsilon}
$$

where $\beta$ is a constant, and $\tilde{\varepsilon}$ is a zero-mean random variable independent of $\tilde{S}$. According to Eq. (15), $\tilde{\theta}$ and $\tilde{S}$ are negatively or positively correlated depending on whether $\beta$ is negative or positive, respectively. They are uncorrelated if $\beta=0$.

Consider first the case that the firm possesses the quadratic utility function, $U(\Pi)=$ $a \Pi-b \Pi^{2} / 2$. We can write Eq. (6) as

$$
\operatorname{Cov}\left\{a-b\left\{\tilde{\theta} \tilde{S} P Q^{*}+[\mathrm{E}(\tilde{S})-\tilde{S}] H^{*}-C\left(Q^{*}\right)\right\}, \tilde{S}\right\}=0
$$

Using Eq. (15), we solve Eq. (16) to yield ${ }^{9}$

$$
H^{*}=\left\{1+\frac{\beta \mathrm{E}\left\{[\tilde{S}-\mathrm{E}(\tilde{S})]^{2} \tilde{S}\right\}}{\operatorname{Var}(\tilde{S})}\right\} P Q^{*}
$$

The following proposition is an immediate consequence of Eq. (17).

Proposition 3. Given that the competitive exporting firm possesses the quadratic utility function, $U(\Pi)=a \Pi-b \Pi^{2} / 2$, and can trade the unbiased currency futures contracts, and that the revenue shock, $\tilde{\theta}$, and the random spot exchange rate, $\tilde{S}$, are characterized by Eq. (15), the firm optimally opts for an under-hedge (over-hedge), i.e., $H^{*}<(>) P Q^{*}$, if $\tilde{\theta}$ and

\footnotetext{
${ }^{8}$ In Section V, we develop two examples to show the possibility that the firm optimally produces more, not less, when the revenue shock is present than when it is absent under the more reasonable assumption of either constant or decreasing absolute risk aversion.

${ }^{9}$ Since $\tilde{\varepsilon}$ is independent of $\tilde{S}$, we have $\operatorname{Cov}(\tilde{\varepsilon} \tilde{S}, \tilde{S})=\mathrm{E}\left(\tilde{\varepsilon} \tilde{S}^{2}\right)-\mathrm{E}(\tilde{\varepsilon} \tilde{S}) \mathrm{E}(\tilde{S})=0$.
} 
$\tilde{S}$ are negatively (positively) correlated, i.e., $\beta<(>)$ 0, or a full-hedge, i.e., $H^{*}=P Q^{*}$, if $\tilde{\theta}$ and $\tilde{P}$ are uncorrelated, i.e., $\beta=0$.

The intuition for Proposition 3 is as follows. Given that covariances can be interpreted as marginal variances, Eq. (6) implies that the optimal futures position, $H^{*}$, is the one that minimizes the variance of the firm's marginal utility, $U^{\prime}\left(\tilde{\Pi}^{*}\right)$, which is tantamount to minimize the variability of the firm's home currency profit at date $1, \tilde{\Pi}^{*}$, given the quadratic utility function. If $\beta=0$, the risk exposure that comes from the last term on the right-hand side of Eq. (8) is not hedgeable by trading the unbiased futures contracts since $\tilde{\theta}$ and $\tilde{S}$ are independent. To minimize the risk exposure due to the second last term on the right-hand side of Eq. (8), the firm optimally opts for a full-hedge, i.e., $H^{*}=P Q^{*}$. We refer to this as the full-hedging motive. If $\beta<(>) 0$, Eq. (15) implies that $\operatorname{Cov}[(\tilde{\theta}-1) \tilde{S}, \tilde{S}]=$ $\beta \mathrm{E}\left\{[\tilde{S}-\mathrm{E}(\tilde{S})]^{2} \tilde{S}\right\}<(>)$. The firm as such is induced to opt for a long (short) futures position so as to reduce the risk exposure arising from the last term on the right-hand side of Eq. (8). We refer to this as the correlation motive. Combining the full-hedging and correlation motives gives rise to the optimality of an under-hedge (over-hedge), i.e., $H^{*}<(>) P Q^{*}$, if $\beta<(>) 0$.

As convincingly argued by Kimball $(1990,1993)$, prudence, i.e., $U^{\prime \prime \prime}(\Pi)>0$, is a reasonable behavioral assumption for decision making under multiple sources of uncertainty. Prudence measures the propensity to prepare and forearm oneself under uncertainty, vis-àvis risk aversion that is how much one dislikes uncertainty and would turn away from it if one could. As is shown by Drèze and Modigliani (1972), Kimball (1990), and Leland (1968), prudence is both necessary and sufficient to induce precautionary saving. Furthermore, prudence is implied by decreasing absolute risk aversion (DARA), which is instrumental in yielding many intuitively appealing comparative statics under uncertainty (Gollier, 2001). As recently pointed out by Bonilla and Vergara (2013), prudence is in fact consistent with not only DARA but also increasing absolute risk aversion (IARA). To see this, we take the following utility function (Pratt, 1964) as an example: $U(\Pi)=-(\theta-\Pi)^{\gamma}$, where $\theta$ and $\gamma$ are positive constants such that $\theta>\Pi$ and $\gamma>2$. The Arrow-Pratt measure of 
absolute risk aversion is then given by $A(\Pi)=-U^{\prime \prime}(\Pi) / U^{\prime}(\Pi)=(\gamma-1) /(\theta-\Pi)$. Since $A^{\prime}(\Pi)=(\gamma-1) /(\theta-\Pi)^{2}>0$ and $U^{\prime \prime \prime}(\Pi)=\gamma(\gamma-1)(\gamma-2)(\theta-\Pi)^{\gamma-3}>0$, we conclude that $U(\Pi)=-(\theta-\Pi)^{\gamma}$ exhibits both IARA and prudence.

The following proposition characterizes the prudent firm's optimal futures position, $H^{*}$.

Proposition 4. Given that the competitive exporting firm is prudent, i.e., $U^{\prime \prime \prime}(\Pi)>0$ for all $\Pi>0$, and can trade the unbiased currency futures contracts, and that the revenue shock, $\tilde{\theta}$, and the random spot exchange rate, $\tilde{S}$, are characterized by Eq. (15), the firm optimally opts for an under-hedge, i.e., $H^{*}<P Q^{*}$, if $\tilde{\theta}$ and $\tilde{S}$ are either uncorrelated or negatively correlated, i.e., $\beta \leq 0$.

Proof. See Appendix B.

The intuition for Proposition 4 is as follows. Given that covariances can be interpreted as marginal variances, Eq. (6) implies that the optimal futures position, $H^{*}$, is the one that minimizes the variance of the firm's marginal utility, $U^{\prime}\left(\tilde{\Pi}^{*}\right)$. Viewing the last term on the right-hand side of Eq. (8) as zero-mean background risk, we observe that its magnitude increases with an increase in the realized spot exchange rate, $S$. The firm, being prudent, has a precautionary motive to shift its home currency profit at date 1 from states with small background risk to states with large background risk so as to mitigate the loss of utility (Eeckhoudt and Schlesinger, 2006). Such a precautionary motive calls for a long futures

position. If $\beta<(>) 0$, the correlation motive reinforces (counteracts) the precautionary motive. Combining these two motives with the full-hedging motive, the prudent firm finds it optimal to opt for an under-hedge, i.e., $H^{*}<P Q^{*}$, if $\beta \leq 0$, and the optimal futures position becomes indeterminate if $\beta>0$.

\section{EXAMPLES}

To gain more insight into the firm's optimal export and hedging decisions, we construct 
two reasonable examples that have closed form solutions. In the first example, we assume that the revenue shock, $\tilde{\theta}$, and the random spot exchange rate, $\tilde{S}$, are characterized by Eq. (15) such that $\tilde{\varepsilon}$ is a standard normal random variable. We assume further that $\tilde{S}$ takes on a low value, $\underline{S}$, with probability $p$, and a high value, $\bar{S}$, with probability $1-p$, where $0<\underline{S}<\bar{S}$ and $0<p<1$. The expected spot exchange rate as such is given by $\mathrm{E}(\tilde{S})=p \underline{S}+(1-p) \bar{S}$. The firm's preferences exhibit constant absolute risk aversion (CARA) so that $U(\Pi)=-e^{-\alpha \Pi}$, where $\alpha>0$ is the constant coefficient of absolute risk aversion. ${ }^{10}$

The first-order conditions for this example are given by

$$
\begin{aligned}
& p \mathrm{E}_{\varepsilon}\left\{e^{-\alpha \tilde{\Pi}^{*}(\underline{S})}\left\{\{1+\beta[\underline{S}-\mathrm{E}(\tilde{S})]+\tilde{\varepsilon}\} \underline{S} P-C^{\prime}\left(Q^{*}\right)\right\}\right\} \\
& \quad+(1-p) \mathrm{E}_{\varepsilon}\left\{e^{-\alpha \tilde{\Pi}^{*}(\bar{S})}\left\{\{1+\beta[\bar{S}-\mathrm{E}(\tilde{S})]+\tilde{\varepsilon}\} \bar{S} P-C^{\prime}\left(Q^{*}\right)\right\}\right\}=0
\end{aligned}
$$

and

$$
p \mathrm{E}_{\varepsilon}\left[e^{-\alpha \tilde{\Pi}^{*}(\underline{S})}\right][\underline{S}-\mathrm{E}(\tilde{S})]+(1-p) \mathrm{E}_{\varepsilon}\left[e^{-\alpha \tilde{\Pi}^{*}(\bar{S})}\right][\bar{S}-\mathrm{E}(\tilde{S})]=0
$$

where $\tilde{\Pi}^{*}(S)=\mathrm{E}(\tilde{S}) P Q^{*}-C\left(Q^{*}\right)+[S-\mathrm{E}(\tilde{S})]\left(P Q^{*}-H^{*}+\beta S P Q^{*}\right)+\tilde{\varepsilon} S P Q^{*}$, and $\mathrm{E}_{\varepsilon}(\cdot)$ is the expectation operator with respect to the standard normal random variable, $\tilde{\varepsilon}$. Since $\mathrm{E}(\tilde{S})=p \underline{S}+(1-p) \bar{S}$, Eq. (19) reduces to $\mathrm{E}_{\varepsilon}\left[e^{-\alpha \tilde{\Pi}^{*}(\underline{S})}\right]=\mathrm{E}_{\varepsilon}\left[e^{-\alpha \tilde{\Pi}^{*}(\bar{S})}\right]$. Substituting this equation into Eq. (18), and using the fact that $\tilde{\varepsilon}$ is a standard normal random variable, yields

$$
\mathrm{E}(\tilde{S}) P+\beta p(1-p)(\bar{S}-\underline{S})^{2} P-\alpha\left[p \underline{S}^{2}+(1-p) \bar{S}^{2}\right] P^{2} Q^{*}-C^{\prime}\left(Q^{*}\right)=0 .
$$

Solving $\mathrm{E}_{\varepsilon}\left[e^{-\alpha \tilde{\Pi}^{*}(\underline{S})}\right]=\mathrm{E}_{\varepsilon}\left[e^{-\alpha \tilde{\Pi}^{*}(\bar{S})}\right]$ by using the fact that $\tilde{\varepsilon}$ is a standard normal random variable yields

$$
H^{*}=P Q^{*}+\left\{\beta[p \bar{S}+(1-p) \underline{S}]-\frac{\alpha}{2}(\underline{S}+\bar{S}) P Q^{*}\right\} P Q^{*} .
$$

\footnotetext{
${ }^{10} \mathrm{CARA}$ implies prudence since $U^{\prime \prime \prime}(\Pi)=\alpha^{3} e^{-\alpha \Pi}>0$ for all $\Pi>0$.
} 
In Appendix C, we show that $Q^{*}$ and $H^{*}$ are both increasing in $\beta$. Solving Eq. (20) for the critical value, $\beta^{\circ}$, of $\beta$ at which $Q^{*}=Q^{\circ}$ yields

$$
\beta^{\circ}=\frac{\alpha\left[p \underline{S}^{2}+(1-p) \bar{S}^{2}\right] P Q^{\circ}}{p(1-p)(\bar{S}-\underline{S})^{2}}>0
$$

Since $\mathrm{d} Q^{*} / \mathrm{d} \beta>0$, we have $Q^{*}>(<) Q^{\circ}$ if $\beta>(<) \beta^{\circ}$. These results are consistent with the findings of Proposition 1 that $Q^{*}<Q^{\circ}$ should $\tilde{\theta}$ and $\tilde{S}$ be uncorrelated or negatively correlated. Indeed, for all $\beta \in\left(0, \beta^{\circ}\right)$, it remains true that $Q^{*}<Q^{\circ}$. However, if $\beta>\beta^{\circ}$, we have $Q^{*}>Q^{\circ}$, which is consistent with the results of Proposition 2. This is particularly the case when the firm is not too risk averse, i.e., when $\alpha$ is closer to zero so that the threshold value, $\beta^{\circ}$, is also closer to zero, as is evident from Eq. (22). A positive correlation between $\tilde{\theta}$ and $\tilde{S}$ is then likely to be sufficient to induce the firm to produce beyond the optimal output level in the absence of the revenue shock.

When $\beta=\beta^{\circ}$, we have $Q^{*}=Q^{\circ}$ so that Eq. (21) becomes

$$
H^{*}=P Q^{\circ}+\frac{\alpha\left[p(1-p)\left(\underline{S}^{3}+\bar{S}^{3}\right)+p(1+p) \underline{S}^{2} \bar{S}+(1-p)(2-p) \underline{S} \bar{S}^{2}\right] P^{2} Q^{\circ 2}}{2 p(1-p)(\bar{S}-\underline{S})^{2}},
$$

where we have used Eq. (22). Eq. (23) implies that $H^{*}>P Q^{*}$ when $\beta=\beta^{\circ}$. It then follows from Eq. (21) and $\mathrm{d} H^{*} / \mathrm{d} \beta>0$ that there exists a unique threshold, $\beta^{*} \in\left(0, \beta^{\circ}\right)$, that solves $\beta^{*}[p \bar{S}+(1-p) \underline{S}]=\alpha(\underline{S}+\bar{S}) P Q^{*} / 2$. Hence, we have $H^{*}<(>) P Q^{*}$ if $\beta<(>) \beta^{*}$. From Proposition 4, we know that the correlation motive counteracts the precautionary motive whenever $\beta>0$. As $\beta$ increases, the correlation motive gets stronger and soon dominates the precautionary motive once $\beta$ exceeds the threshold, $\beta^{*}$, thereby rendering the optimality of an over-hedge, i.e., $H^{*}>P Q^{*}$.

Finally, we construct another example wherein the firm has a power utility function, $U(\Pi)=\Pi^{\eta}$, where $\eta \in(0,1)$ is a constant. The Arrow-Pratt measure of absolute risk aversion is given by $A(\Pi)=-U^{\prime \prime}(\Pi) / U^{\prime}(\Pi)=(1-\eta) / \Pi$ so that the firm's preferences exhibit decreasing absolute risk aversion (DARA). Suppose that the revenue shock, $\tilde{\theta}$, and the random spot exchange rate, $\tilde{S}$, are perfectly positively correlated in that both of them take on low values, $\underline{\theta}$ and $\underline{S}$, with probability $p$, and high values, $\bar{\theta}$ and $\bar{S}$, with probability 
$1-p$, where $0<\underline{\theta}<1<\bar{\theta}, 0<\underline{S}<\bar{S}$, and $0<p<1$. The expected value of the revenue shock is given by $\mathrm{E}(\tilde{\theta})=p \underline{\theta}+(1-p) \bar{\theta}=1$, and the expected spot exchange rate is given by $\mathrm{E}(\tilde{S})=p \underline{S}+(1-p) \bar{S}$.

The first-order conditions for this example are given by

$$
\begin{aligned}
p \eta\{\underline{\theta S} & \left.P Q^{*}+[\mathrm{E}(\tilde{S})-\underline{S}] H^{*}-C\left(Q^{*}\right)\right\}^{\eta-1}\left[\underline{\theta S} P-C^{\prime}\left(Q^{*}\right)\right] \\
& +(1-p) \eta\left\{\overline{\theta \bar{S}} P Q^{*}+[\mathrm{E}(\tilde{S})-\bar{S}] H^{*}-C\left(Q^{*}\right)\right\}^{\eta-1}\left[\overline{\theta S} P-C^{\prime}\left(Q^{*}\right)\right]=0
\end{aligned}
$$

and

$$
\begin{aligned}
p \eta\{\underline{\theta} \underline{S} & \left.P Q^{*}+[\mathrm{E}(\tilde{S})-\underline{S}] H^{*}-C\left(Q^{*}\right)\right\}^{\eta-1}[\mathrm{E}(\tilde{S})-\underline{S}] \\
& +(1-p) \eta\left\{\overline{\theta S} P Q^{*}+[\mathrm{E}(\tilde{S})-\bar{S}] H^{*}-C\left(Q^{*}\right)\right\}^{\eta-1}[\mathrm{E}(\tilde{S})-\bar{S}]=0 .
\end{aligned}
$$

Since $\mathrm{E}(\tilde{S})=p \underline{S}+(1-p) \bar{S}$, Eq. (25) implies that

$$
H^{*}=\left(\frac{\overline{\theta S}-\underline{\theta S}}{\bar{S}-\underline{S}}\right) P Q^{*}>P Q^{*},
$$

since $0<\underline{\theta}<1<\bar{\theta}$ and $0<\underline{S}<\bar{S}$. Substituting Eq. (26) into Eq. (24) yields

$$
p \underline{\theta \underline{S}} P+(1-p) \overline{\theta S} P-C^{\prime}\left(Q^{*}\right)=0 .
$$

Note that $p \underline{\theta} \underline{S}+(1-p) \bar{\theta} \bar{S}=p \underline{S}+(1-p) \bar{S}+p(1-\underline{\theta})(\bar{S}-\underline{S})$ since $p \underline{\theta}+(1-p) \bar{\theta}=1$. It then follows from Eq. (27) that $Q^{*}>Q^{\circ}$. Hence, in this example of DARA preferences, the results of Propositions 2 and 3 remain valid.

\section{CONCLUSION}

In this paper, we examine the behavior of a competitive exporting firm that faces not only exchange rate uncertainty but also a multiplicative shock to its foreign currency revenue. While the revenue shock is neither hedgeable nor insurable, the firm can hedge its exchange 
rate risk exposure by trading unbiased currency futures contracts. We show that both the separation and full-hedging theorems fail to hold in the presence of the revenue shock. The correlation between the revenue shock and the random spot exchange rate plays a pivotal role in determining the firm's optimal export and hedging decisions. Specifically, if this correlation is non-positive, the firm optimally produces less in the presence than in the absence of the revenue shock. If, in addition, the firm's preferences satisfy prudence à la Kimball $(1990,1993)$, the optimal futures position is an under-hedge. When the correlation between the revenue shock and the random spot exchange rate is positive, we derive sufficient conditions under which the prevalence of the revenue shock induces the firm to increase its optimal output level. Using two reasonable examples that have closed form solutions, we further show that an over-hedge is optimal if the correlation is sufficiently positive. Our results as such suggest that operational hedging and financial hedging interact in a rather complicated way under joint revenue and exchange rate risk. As multiple sources of uncertainty are a fact of life, future research along this line is warranted to further enhance our understanding of how firms should devise their risk management strategies in practice (Brown and Toft, 2002; Korn, 2010).

\section{REFERENCES}

Adam-Müller, A. F. A. (1997). 'Export and hedging decisions under revenue and exchange rate risk: a note', European Economic Review, 41, pp. 1421-26.

Adam-Müller, A. F. A. and Nolte, I. (2011). 'Cross hedging under multiplicative basis risk', Journal of Banking and Finance, 35, pp. 2956-64.

Anderson, R. W. and Danthine, J.-P. (1981). 'Cross hedging', Journal of Political Economy, 89, pp. 1182-96.

Benninga, S., Eldor, R. and Zilcha, I. (1985). 'Optimal international hedging and output policies in commodity and currency forward markets', Journal of International Money and Finance, 4, pp. 537-52. 
Bonilla, C. A. and Vergara, M. (2013). 'Credit rationing or entrepreneurial risk aversion? A comment', Economics Letters, 120, pp. 329-31.

Broll, U. (1992). 'The effect of forward markets on multinational firms', Bulletin of Economic Research, 44, pp. 233-40.

Broll, U. (1997). 'Cross hedging in currency forward markets: a note', Journal of Futures Markets, 17, pp. 475-82.

Broll, U. and Wong, K. P. (1999). 'Hedging with mismatched currencies', Journal of Futures Markets, 19, pp. 859-75.

Broll, U., Wong, K. P. and Zilcha, I. (1999). 'Multiple currencies and hedging', Economica, 66, pp. $421-32$.

Broll, U. and Zilcha, I. (1992). 'Exchange rate uncertainty, futures markets and the multinational firm', European Economic Review, 36, pp. 815-26.

Brown, G. W. and Toft, K.-B. (2002). 'How firms should hedge', Review of Financial Studies, 14, pp. 1283-324.

Chang, E. C. and Wong, K. P. (2003). 'Cross-hedging with currency options and futures', Journal of Financial and Quantitative Analysis, 38, pp. 555-74.

Drèze, J. H. and Modigliani, F. (1972). 'Consumption decisions under uncertainty', Journal of Economic Theory, 5, pp. 308-35.

Eeckhoudt, L. and Schlesinger, H. (2006). 'Putting risk in its proper place', American Economic Review, 96, pp. 280-9.

Froot, K. A., Scharfstein, D. S. and Stein, J. C. (1993). 'Risk management: coordinating corporate investment and financing policies', Journal of Finance, 48, pp. 1629-58.

Goldberg, P. K. and Knetter, M. M. (1997). 'Goods prices and exchange rates: what have we learned?', Journal of Economic Literature, 35, pp. 1243-72.

Gollier, C. (2001). The economics of risk and time, Cambridge, MA: MIT Press.

Gust, C., Leduc, S. and Vigfusson, R. J. (2010). 'Trade integration, competition, and 
the decline in exchange-rate pass-through', Journal of Monetary Economics, 57, pp. 309-24.

Holthausen, D. M. (1979). 'Hedging and the competitive firm under price uncertainty', American Economic Review, 69, pp. 989-95.

Katz, E. and Paroush, J. (1979). 'The effect of forward markets on exporting firms', Economics Letters, 4, pp. 272-4.

Kawai, M. and Zilcha, I. (1986). 'International trade with forward-futures markets under exchange rate and price uncertainty', Journal of International Economics, 20, pp. 8398.

Kim, J.-C., \& Song, K. (2010). 'Investment barriers and premiums on closed-end country funds', International Review of Economics and Finance, 19, pp. 615-626.

Kimball, M. S. (1990). 'Precautionary saving in the small and in the large', Econometrica, 58 , pp. $53-73$.

Kimball, M. S. (1993). ‘Standard risk aversion', Econometrica, 61, pp. 589-611.

Korn, O. (2010). 'How firms should hedge: an extension', Journal of Futures Markets, 30, pp. $834-45$.

Leland, H. E. (1968). 'Saving and uncertainty: the precautionary demand for saving', Quarterly Journal of Economics, 82, pp. 465-73.

Marazzi, M. and Sheets, N. (2007). 'Declining exchange rate pass-through to US import prices: the potential role of global factors', Journal of International Money and Finance, 26, pp. 924-47.

Pratt, J. W. (1964). 'Risk aversion in the small and in the large', Econometrica, 32, pp. $122-36$.

Sandmo, A. (1971). 'On the theory of the competitive firm under price uncertainty', American Economic Review, 61, pp. 65-73.

Smith, C. W. and Stulz, R. M. (1985). 'The determinants of firms' hedging policies', Journal 
of Financial and Quantitative Analysis, 20, pp. 391-405.

Stulz, R. M. (1984). 'Optimal hedging policies', Journal of Financial and Quantitative Analysis, 19, pp. 127-40.

Stulz, R. M. (1990). 'Managerial discretion and optimal financial policies', Journal of Financial Economics, 26, pp. 3-27.

Tufano, P. (1996). 'Who manages risk? An empirical examination of risk management practices in the gold mining industry', Journal of Finance, 51, pp. 1097-137.

Viaene, J.-M. and Zilcha, I. (1998). 'The behavior of competitive exporting firms under multiple uncertainty', International Economic Review, 39, pp. 591-609.

Wong, K. P. (2003). 'Currency hedging with options and futures', European Economic Review, 47, pp. 833-9.

Wong, K. P. (2007). 'Optimal export and hedging decisions when forward markets are incomplete', Bulletin of Economic Research, 59, pp. 67-81.

Wong, K. P. (2013). 'Cross hedging with currency forward contracts', Journal of Futures Markets, 33, pp. 653-74. 